\title{
Ontogenic Resistance to Uncinula necator Varies by Genotype and Tissue Type in a Diverse Collection of Vitis spp.
}

\author{
Christopher T. Gee and David M. Gadoury, Department of Plant Pathology, Cornell University, Geneva, NY \\ 14456; and Lance Cadle-Davidson, USDA-ARS, Grape Genetics Research Unit, Geneva, NY 14456
}

\begin{abstract}
Gee, C. T., Gadoury, D. M., and Cadle-Davidson, L. 2008. Ontogenic resistance to Uncinula necator varies by genotype and tissue type in a diverse collection of Vitis spp. Plant Dis. 92:1067-1073.

Berries of grapevine (Vitis spp.) have a limited window of susceptibility to Uncinula necator, the causal agent of grapevine powdery mildew, until the onset of ontogenic resistance approximately 2 to 3 weeks postbloom. This phenomenon has been demonstrated in several cultivars of $V$. vinifera and in V. labruscana 'Concord', which all exhibited a similar duration of susceptibility. To identify genetic variation for ontogenic resistance, we screened a diverse collection of Vitis species and interspecific hybrids maintained in the USDA-ARS cold-hardy Vitis germplasm collection in Geneva, NY. Of the 79 genotypes whose fruit clusters were screened for susceptibility to powdery mildew under field conditions, 50 exhibited a high level of constitutive resistance to powdery mildew and did not develop more than trace levels of disease when inoculated, irrespective of the stage of berry development at inoculation. Twenty-four genotypes exhibited a significant gain of resistance as berries aged. This ontogenic resistance was conserved across four species and several interspecific hybrids of Vitis spp., although the timing of the onset of ontogenic resistance varied by genotype. The mechanism of ontogenic resistance was examined for four genotypes. Similar to previous studies, ontogenic resistance greatly reduced the incidence of successful penetration. Despite the broad conservation of ontogenic resistance across species, one genotype ( $V$. rupestris 'R-65-44') remained susceptible past the onset of ripening, over 1 month later than reported previously for V. vinifera and V. labruscana. Variation in the resistance phenotype was observed among the rachis, pedicels, and berries within clusters of the majority of genotypes studied. The genetic variation in ontogenic resistance, in particular the discovery of a genotype in which berries remain susceptible as they mature, will facilitate further study of the inheritance and molecular basis of ontogenic resistance.
\end{abstract}

Additional keywords: adult plant resistance, age-related resistance, Erysiphe necator, genetic resources

The interaction between pathogens and their plant hosts is dynamic, with susceptibility changing as whole plants, organs, and specific tissues age. The principal terms used to describe this process include age-related resistance, adult plant resistance, and ontogenic resistance $(3,11$, 16,21). Broadly defined, such developmentally regulated resistance is exhibited toward many plant pests, including fungi,

Corresponding author: Lance Cadle-Davidson E-mail: Lance.CadleDavidson@ars.usda.gov

Mention of trade names or commercial products is solely for the purpose of providing specific information and does not imply recommendation or endorsement by the U.S. Department of Agriculture.

* The $\boldsymbol{e}$-Xtra logo stands for "electronic extra" and indicates that Figures 2, 3, and 5 appear in color in the online edition.

Accepted for publication 21 February 2008.

doi:10.1094/PDIS-92-7-1067

This article is in the public domain and not copyrightable. It may be freely reprinted with customary crediting of the source. The American Phytopathological Society, 2008. viruses, bacteria, nematodes, oomycetes, and insects, and ranges from partial resistance to immunity $(2,6,12,13-16,18)$.

In grapevine (Vitis spp.), berries of $V$. vinifera and the interspecific $V$. vinifera hybrid $V$. labruscana 'Concord' (1) are highly susceptible to infection by grapevine powdery mildew (Uncinula necator (Schwein.) Burrill, syn. Erysiphe necator) for a period beginning with bloom and lasting approximately 2 to 3 weeks $(8,10,11,21)$. After this time period, susceptibility rapidly decreases until the berries develop ontogenic resistance, characterized by near-immunity to subsequent infection or to further colonization by existing infections $(10,11)$. The cause of this resistance remains elusive but is attributed neither to factors commonly involved in age-related resistances, such as thickening of the berry cuticle or the anticlinal cell wall, nor to the formation of papillae or typical PR gene products (e.g., thaumatin and chitinase) (7). This gain of resistance is expressed differently in separate tissues of the cluster (i.e., rachis, berries) (10), which may be due to differences in timing of the onset of resistance, or to a different mechanism.
In previous studies, several genotypes of Vitis exhibited a gain of resistance that occurred on a similar time-frame and apparently halted the pathogen attack at the cuticle immediately prior to penetration $(8,10,11,21)$. The lack of variation hindered studies of the genetic basis of ontogenic resistance, as it was impossible to separate resistance factors from factors related to normal berry development. Additional progress in understanding ontogenic resistance would be greatly aided by discovery of genetic variation in the trait. Thus, we began a more comprehensive search for variation in ontogenic resistance within Vitis spp., in which we assessed the temporal distribution of resistance to $U$. necator among a genetically diverse collection of 79 host genotypes. These genotypes included six Vitis species and several Vitis interspecific hybrids maintained in the USDA-ARS cold-hardy Vitis germplasm collection. Tissue specificity of ontogenic resistance to $U$. necator was also quantified and characterized within this collection.

\section{MATERIALS AND METHODS}

Vineyard and treatments. Twentyyear-old field-grown vines at the USDAARS cold-hardy Vitis germplasm collection located in Geneva, NY, were used in these experiments. Seventy-nine genotypes of female and hermaphroditic vines were selected for evaluation for the gain of ontogenic resistance. Each genotype in the germplasm collection is represented by two adjacent, replicate, own-rooted vines planted on $1.8-\mathrm{m}$ centers using a threewire trellis, cane-pruned, and trained to the Umbrella Kniffin system. Each genotype was tracked using the unique plant introduction (PI) number taken from the USDA-ARS Germplasm Resources Information Network (GRIN) database (23). To limit contamination of clusters with natural powdery mildew prior to inoculation, the vineyard was sprayed every 14 days using a typical commercial spray program consisting of locally systemic and contact fungicides (10). To ensure that clusters selected for inoculation were protected from chemical sprays, clusters were covered with plastic bags prior to fungicide application as previously described (10).

Primary basal clusters were randomly assigned to inoculations targeted at 4,8 , 15 , 21, or 28 days postbloom (DPB), unless otherwise stated. Each treatment 
consisted of two replicate clusters on each of the two adjacent replicate vines. Bloom was defined as the point at which the calyptras of $50 \%$ of flowers within a cluster had dehisced. On each vine, a single cluster was protected from fungicide application but left uninoculated to ascertain the natural levels of infection within the experimental vineyard. To limit the numbers of clusters to be inoculated, genotypes with less than $10 \%$ severity-defined as the susceptibility threshold-at all timepoints in 2004 were inoculated at only one early (6 DPB) and one late (27 DPB) timepoint in both 2005 and 2006, to confirm resistance.

Inoculum preparation and cluster inoculations. Conidial inoculum was raised on grapevine seedlings grown from seeds harvested from either $V$. vinifera 'Riesling' or $V$. vinifera 'Chardonnay'. Germinated seeds were sown in 3-inch pots and grown to the fourth-leaf stage in a greenhouse under natural light conditions, then placed in an environment-controlled growth chamber set at $25^{\circ} \mathrm{C}$ with $12 \mathrm{~h}$ of light. In all 3 years of the study, mixtures of sexually incompatible isolates were released into the chamber to start an epidemic, which was maintained with the addition of new seedlings.

Heavily mildewed leaves with actively growing colonies were vortexed in $18.2 \mathrm{M} \Omega$ water (Barnstead E-Pure, Dubuque, IA) with $0.005 \%$ Tween 20 (SigmaAldrich, St. Louis, MO) to suspend the conidia. Spore density was corrected to $10^{5}$ conidia/ml after quantification using a hemacytometer. The spore suspension was sprayed onto clusters until droplet runoff using a handheld atomizer (Preval, PrecisionValve, Yonkers, NY), using care to prevent unintended inoculations. Spore suspensions were discarded and prepared fresh every $30 \mathrm{~min}$ to promote high spore viability.

Data collection, management, and statistical analysis. Clusters were marked with unique bar codes affixed to slip-on tags hung around the rachis of the cluster prior to bloom. Bar codes were tracked using a Symbol MC50 handheld computer (Motorola, Inc., Holtsville, NY), which used custom software to interface with the database while in the vineyard. All clusters were tracked for bloom and inoculation dates, as well as for disease severity and cluster survival.

Following an incubation of 6 to 9 weeks postinoculation, clusters were assessed macroscopically by visually estimating the percentage of surface covered by powdery mildew using $5 \%$ increments. Within a cluster, the rachis, pedicels, and berries were separately rated for disease. The same person (C.T.G.) assessed disease

Table 1. Phenotypic classification of genotypes with susceptible berries, organized by berry phenotype

\begin{tabular}{|c|c|c|c|c|c|c|c|c|}
\hline \multirow[b]{2}{*}{$\begin{array}{l}\text { Berry classification } \\
\text { PI }^{\mathbf{b}}\end{array}$} & \multirow[b]{2}{*}{ Vitis species $^{c}$} & \multirow[b]{2}{*}{ Variety $^{d}$} & \multicolumn{4}{|c|}{ Berry } & \multirow[b]{2}{*}{$\begin{array}{c}\text { Rachis } \\
\text { classification }\end{array}$} & \multirow[b]{2}{*}{$\begin{array}{c}\text { Pedicel } \\
\text { classification }\end{array}$} \\
\hline & & & $\begin{array}{c}\text { Early } \\
\text { severity } \\
(\%)^{\mathrm{e}}\end{array}$ & $P$ value ${ }^{f}$ & $\begin{array}{c}\text { Late } \\
\text { severity } \\
(\%)^{\mathrm{g}}\end{array}$ & $\begin{array}{c}\text { Predicted } \\
\text { time of } \\
<10 \% \text { severity }\end{array}$ & & \\
\hline \multicolumn{9}{|l|}{ OR } \\
\hline 588296 & V. hybrid & Red Amber (Minn 25) & 30.6 & $<0.001$ & 0.0 & 171.4 & SU & SU \\
\hline 588313 & V. hybrid & Carman & 25.5 & $<0.001$ & 0.0 & 19.8 & $\mathrm{SU}$ & OR \\
\hline 588340 & V. hybrid & Unknown & 18.9 & 0.022 & 5.8 & 202.7 & SU & SU \\
\hline 588430 & V. hybrid & Wapanuka & 12.4 & 0.084 & 8.8 & 68.2 & $\mathrm{SU}$ & SU \\
\hline 588474 & V. hybrid & NY 66.760 .2 & 22.0 & $<0.001$ & 6.3 & 184.7 & $\mathrm{SU}$ & SU \\
\hline 588477 & V. hybrid & NY 65.556 .1 & 31.1 & $<0.001$ & 1.5 & 185.1 & SU & SU \\
\hline 588484 & V. hybrid & NY 65.591 .1 & 39.3 & $<0.001$ & 5.6 & 276.9 & SU & SU \\
\hline 588504 & V. hybrid & NY 65.546 .3 & 35.7 & $<0.001$ & 1.5 & 225.3 & SU & OR \\
\hline 588505 & V. hybrid & NY 65.562.2 & 11.2 & $<0.001$ & 0.0 & 35.2 & NS & NS \\
\hline 588517 & V. hybrid & Ill 487-1 & 12.9 & 0.004 & 0.0 & 65.8 & SU & SU \\
\hline 588519 & V. hybrid & NY 65.575 .1 & 38.1 & $<0.001$ & 0.0 & 284.3 & $\mathrm{SU}$ & SU \\
\hline 588524 & V. hybrid & Ill 803-2 & 20.3 & $<0.001$ & 0.0 & 138.1 & $\mathrm{SU}$ & $\mathrm{SU}$ \\
\hline 588527 & V. hybrid & NY 65.004.1 & 18.0 & $<0.001$ & 0.0 & 131.9 & $\mathrm{SU}$ & SU \\
\hline 588530 & V. hybrid & NY 65.556 .5 & 29.2 & $<0.001$ & 2.5 & 191.7 & $\mathrm{SU}$ & $\mathrm{SU}$ \\
\hline 588550 & V. hybrid & Reinohli & 12.2 & 0.004 & 0.0 & 42.4 & OR & SU \\
\hline 588564 & V. hybrid & John Viola & 16.5 & $<0.001$ & 0.0 & 75.7 & OR & OR \\
\hline 597247 & V. hybrid & Gaertner & 31.7 & $<0.001$ & 0.0 & 114.3 & OR & OR \\
\hline 483147 & V. labrusca & Rem 43-75 & 11.0 & 0.040 & 0.0 & 21.4 & NS & SU \\
\hline 483163 & V. labrusca & Rem NE 36 & 15.2 & 0.003 & 0.0 & 69.1 & $\mathrm{SU}$ & SU \\
\hline 588194 & V. labrusca & Dunkel 1 & 11.3 & 0.053 & 1.3 & 35.0 & NS & $\mathrm{SU}$ \\
\hline 483181 & V. riparia & Rem NE 22 & 13.3 & 0.067 & 0.6 & 80.2 & NS & SU \\
\hline 588225 & $V$. rupestris & $\mathrm{R}-65-47$ & 6.9 & 0.006 & 0.3 & -110.1 & $\mathrm{SU}$ & SU \\
\hline 588231 & $V$. rupestris & Alphonse de Serres & 9.0 & 0.007 & 0.0 & -30.3 & $\mathrm{SU}$ & SU \\
\hline 588401 & $V$. rupestris & RU-66-2 & 14.7 & 0.054 & 0.0 & 83.7 & $\mathrm{SU}$ & SU \\
\hline \multicolumn{9}{|l|}{ SU } \\
\hline 588224 & $V$. rupestris & R-65-44 & 40.2 & 0.021 & 36.7 & 1804.0 & SU & SU \\
\hline \multicolumn{9}{|l|}{ NS } \\
\hline 588217 & $V$. cinerea & В 27 & 9.7 & 0.100 & 0.0 & -9.1 & SU & SU \\
\hline 588398 & $V$. cinerea & Barrett 1 & 11.7 & 0.114 & 0.0 & 22.9 & SU & NS \\
\hline 588493 & V. hybrid & NY 65.586 .1 & 12.3 & 0.187 & 2.6 & 100.8 & $\mathrm{SU}$ & SU \\
\hline 588497 & V. hybrid & NY 65.552 .2 & 14.1 & 0.299 & 0.0 & 77.2 & NS & NS \\
\hline
\end{tabular}

a Classification categories used: OR = ontogenically resistant, $\mathrm{SU}=$ persistently susceptible, NS = nonsignificant.

${ }^{\mathrm{b}} \mathrm{PI}=$ plant introduction number, a unique identifier for each genotype in the GRIN database, where PI is linked with additional information related to that genotype: http://www.ars-grin.gov/npgs/index.html (23).

${ }^{\mathrm{c}}$ Species listed for each genotype, taken from the GRIN database. Vitis interspecific hybrids are listed as $V$. hybrid.

d Variety listed for each genotype, taken from the GRIN database. Genotypes with no variety recorded listed as unknown.

e Early disease severity of berries determined by taking the y-intercept value from the best fit equation using the Fit Model module in JMP v.7.

${ }^{\mathrm{f}} P$ value of the $F$ test for the effect of growing degree days accumulated after bloom and its interaction with year. This calculation uses the Type-I sums of squares from the GLM output of SAS 8.0.

$\mathrm{g}$ Late severity averaged over the last $20 \%$ of the screening period across all years.

${ }^{\mathrm{h}}$ Growing degree days at which berry severity is predicted to fall below $10 \%$, calculated by using the equation for the mean slope for each genotype, as determined using the Fit Model module in JMP v.7. For those genotypes with y-intercepts less than 10\% severity, this number is negative.

i Classification of the rachis using the same criteria developed for berry data.

j Classification of the pedicel using the same criteria developed for berry data. 
severity in all seasons for all tissues. For berry disease assessment, severity on normally developing berries was recorded separately from severity on shot berries, which are stunted in growth and development (5). Cluster age at inoculation was translated from DPB to growing degree days $\left(\mathrm{GDD}\right.$, base $=10^{\circ} \mathrm{C}$ ) postbloom to account for the year-to-year environmental effects. Daily temperature data were obtained from a weather monitoring station located $2.5 \mathrm{~km}$ from the vineyard at the New York State Agricultural Experiment Station in Geneva, NY.

Statistical analysis was carried out using PROC GLM in SAS v.8.0 (SAS Institute, Inc., Cary, NC) using disease severity as the response variable and GDD, field year, and the interaction GDD $\times$ field year as predictors. The type-I sums of squares for GDD and GDD $\times$ field year from the GLM analysis were summed and analyzed in a nested design to determine their contribution to overall significance. $P$ values were determined using the FDIST function in Excel 2003 (Microsoft Corporation, Redmond, WA). The mean slope and intercept of disease severity by GDD for each genotype was determined using the Fit Model module in JMP v.7.0 (SAS Institute). The $y$-intercept of the line of best fit was taken as the maximum severity, or the potential disease severity at time $=0$. The last susceptible time was calculated by setting disease severity $=10 \%$ and using the parameter estimates for the least squares fit (JMP Fit Model module) to solve for GDD.

Genotypes were classified into four phenotypic groups: (i) constitutively resistant (CR), (ii) persistently susceptible (SU), (iii) ontogenic resistant (OR), and (iv) not significant (NS). CR genotypes were always resistant and were therefore defined by having a disease severity of $10 \%$ or less on all inoculated clusters. Of the remaining genotypes, which had susceptibility at some point during development, SU genotypes failed to develop resistance and were therefore classified by having a disease severity greater than $10 \%$ over the last $20 \%$ of the screening period (in GDD), averaged among all years. For the remaining genotypes, categorization of OR required that the statistical analysis described above be statistically significant $(\alpha=0.1)$ (Table 1). These three categories are illustrated in Figure 1 using specific genotypes as examples. Genotypes not fitting into one of the three above categories were labeled as NS, meaning no significant pattern could be applied. Genotypes identified as CR for the berries were not included in the statistical analysis.

Detached berry preparation and epiilluminescence microscopy. In 2006 and 2007, berries were collected 50 to 75 DPB from clusters of selected OR genotypes (PI: 588296, 588484, 588530) and the genotype that was SU (PI: 588224). Prior to inoculation, berries were examined microscopically at $\times 160$ to ensure they were free of prior infection. The berries were placed pedicel-side down onto the rack of an empty pipette-tip box (Rainin Instrument, Oakland, CA) with a moistened filter paper in the bottom to maintain high humidity. Berries were inoculated by dusting them with heavily mildewed leaves with actively sporulating colonies and were incubated in the closed boxes at room temperature $\left(25^{\circ} \mathrm{C}\right)$ for 7 days. Berries were then examined using an epiilluminescence microscope (Zeiss Model 14 , Göttingen, Germany) at $\times 160$ magnification without further processing or staining. Three hundred fifty conidia per genotype were observed and categorized as (i) germinated with an appressorium, (ii) with a nonbranched secondary hypha, or (iii) with branched secondary hyphae. Conidia with a nonbranched secondary hypha were not included in data analysis since they could arise either from a successful penetration or by a conidium capable of growing a second germ tube after the first was unsuccessful. OR genotypes were grouped and compared with the SU genotype. A $\chi^{2}$ test of difference between two proportions was used to determine if a significant difference existed between the proportion of conidia successfully infecting (assessed by the presence of branched secondary hyphae) and those unsuccessful, compared between the resistant and susceptible groups. All replicate experiments were combined, and the ratio of successful to unsuccessful penetration events was compared between the OR group and the SU genotype.

Berry size measurement. In 2006, one uninoculated cluster was marked on each replicate vine for each of eight selected genotypes (PI: 483176, 588224, 588225, 588231, 588258, 588296, 588484, 588530) to monitor berry growth. Prior to bloom, a portion of the cluster containing approximately 20 berries was partitioned using Teflon tape tied loosely around the rachis. Berry diameter was measured, using digital calipers, at the widest part of the berry every 4 days starting at bloom. For each cluster, the two largest diameter values within the partition were averaged to accommodate the presence of shot berries. The measurement date was converted to GDD at each measurement (see above).

\section{RESULTS}

Phenotypic screen and genotypic categorization. For berries, 50 genotypes were resistant at every timepoint (CR), one genotype remained susceptible throughout the timepoints tested (SU), 24 genotypes exhibited a significant gain of resistance (OR) (Figs. 1 and 2), and four genotypes exhibited no statistically significant pattern (NS) (Tables 1 and 2). Categorization for the rachis portion of the cluster did not correspond with berry categorization; of the 79 genotypes, 13 were classified as CR, 41 as SU, seven as OR, and 18 as NS (Tables 1 and 2). Similarly, the categorization of resistance in the pedicel portion of the cluster differed from other tissues, with four genotypes being classified as CR, 41 as SU, 13 as OR, and 21 as NS (Tables 1 and 2).

For berries, the average maximum severity was much higher in the OR group $(20.3 \%)$ than in the CR group $(0.5 \%)$. For normally developing CR berries, 1,104 of 1,137 inoculated clusters had $0 \%$ disease

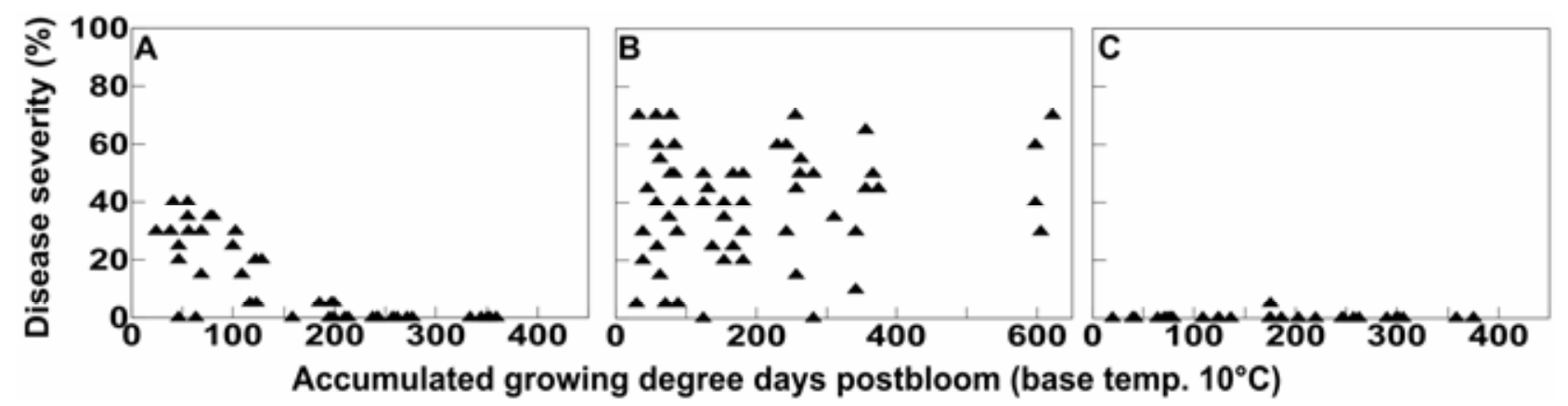

Fig. 1. Graphical representatives of three phenotypic categories used to classify the 79 genotypes screened. All graphs show a composite of 3 years of data for genotypes: A, Vitis hybrid 'Red Amber' (PI: 588296) showing a typical ontogenic gain of resistance (OR); B, V. rupestris 'R-65-44' (PI: 588224) showing persistent susceptibility (SU) well beyond typical development of ontogenic resistance (note x-axis scale); and C, V. hybrid 'Tom's Favorite' (PI: 483176) showing constitutive resistance (CR). Each filled triangle represents disease severity (y-axis) of one or more replicate clusters inoculated at a calculated number of growing degree days after bloom (x-axis). 
severity. However, CR shot berries were frequently infected with powdery mildew (461 of 1,137 clusters), and this susceptibility did not typically diminish with time, as 40 of the 47 CR genotypes with susceptible shot berries retained this susceptibility through 28 DPB.

Berries of the single SU genotype exhibited the highest average maximum severity at $40.2 \%$. By species, the four $V$. rupestris $(17.7 \%)$ and the 26 genotypes of interspecific hybrids including $V . \times$ andersonii, $V . \times$ champinii, and $V . \times$ novae-angliae $(16.8 \%)$ exhibited the highest average maximum severity, while the $V$. riparia $(1.0 \%)$ and $V$. acerfolia $(0.0 \%)$ exhibited the lowest maximum severity. For OR genotypes, resistance was gained in a development period ranging from 21.4 GDD to 284.3 GDD (Table 1). Only four of 230 uninoculated control clusters exhibited any disease, and the average overall severity of control clusters was $0.2 \%$, reflecting very low background levels of powdery mildew in the vineyard.

Conidial germination and colony formation on putatively resistant berries. The proportion of branched secondary hyphae was significantly lower in the OR group than in the SU genotype $(P=$ 0.0005). For the SU genotype $V$. rupestris 'R-65-44' (PI: 588224), 16.2\% of germinated conidia exhibited relatively long and extensively branched secondary, tertiary, and higher-order hyphae (Fig. 3C). On genotypes classified as OR, mildew colonies failed to develop from germinated conidia within 7 days after inoculation (e.g., Fig. 3A). No conidia were able to infect $V$. hybrid 'NY 65.591.1' (PI: 588484) or $V$. hybrid 'NY 65.556.5' (PI: $588530)$. While some conidia (3.2\%) overcame penetration resistance on berries of V. hybrid 'Red Amber' (PI: 588296), growth did not expand beyond $10 \mu \mathrm{m}$ of the initial branch point.

Berry size measurements. Berries from V. rupestris 'R-65-44' (PI: 588224) expanded in a manner similar to all genotypes measured including other $V$. rupestris genotypes (PI: 588225, 588231) (Fig. 4). Further, V. rupestris 'R-65-44' shoots and clusters are characteristic of $V$. rupestris, regardless of phenotypic categorization (Fig. 5).

\section{DISCUSSION}

Ontogenic resistance confers broadspectrum and durable resistance to several grapevine diseases, including powdery mildew (4,9-11,21), downy mildew (14), and black rot (13). Our goal was to identify variation for ontogenic resistance within a diverse collection of Vitis spp. Among 79 genotypes representing six Vitis spp. and several interspecific hybrids, for genotypes exhibiting any susceptibility, ontogenic resistance was highly conserved. However, one genotype ( $V$. rupestris ' $\mathrm{R}$ 65-44') was found to have persistent and reproducible susceptibility (i.e., young berries were highly susceptible and did not acquire resistance as they aged).

Constitutive resistance. Of the genotypes screened in the current study, the majority (50 out of 79) were resistant at all points of development (Table 2). Additionally, disease severity on berries was $0 \%$ in 1,104 of $1,137 \mathrm{CR}$ clusters rated, reflecting strong resistance in these genotypes. This frequency of resistance is not surprising since the germplasm evaluated was highly enriched for wild-genotypes of North American Vitis species (e.g., V. riparia, V. cinerea, $V$. labrusca), which are thought to have co-evolved with powdery mildew $(17,20)$. Co-evolution has been previously demonstrated to enrich the frequency of natural resistance to pests (19).

For investigations of ontogenic resistance, CR genotypes do not provide insight, as there is little or no observable change in susceptibility. However, as a source of powdery mildew resistance for breeding programs, genotypes that exhibited CR could be useful, particularly the three genotypes (PI: 483158, 588257, 588400 ) that were resistant in all tissue types of the cluster. Seven interspecific

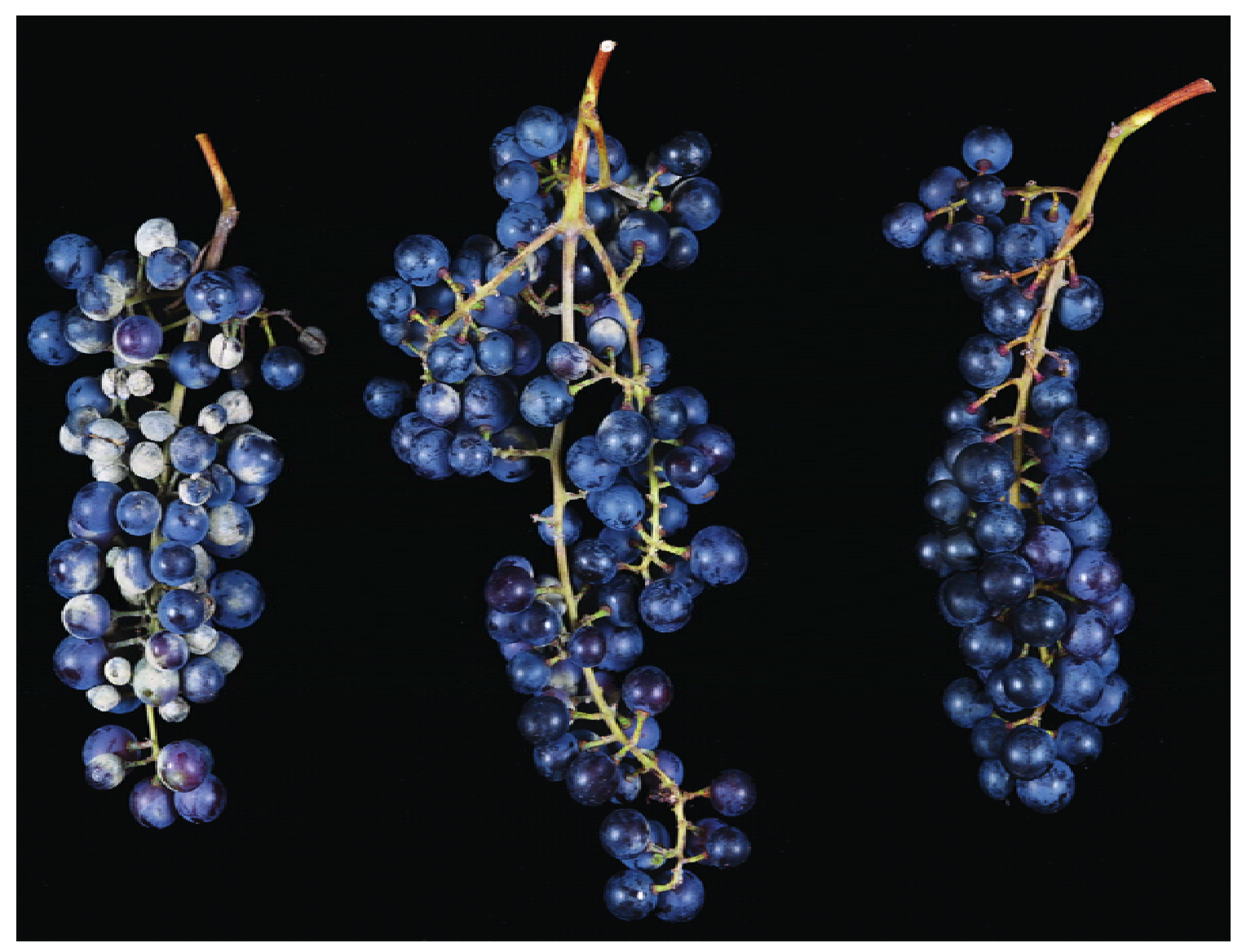

Fig. 2. Clusters from Vitis hybrid 'NY 65.591.1' (PI: 588484) exhibiting development of ontogenic resistance. Clusters were field inoculated, from left to right, at 8,15 , and 21 days postbloom. The earliest inoculation date resulted in extensive disease, the middle date intermediate disease, and the latest no disease. Clusters were collected following six or more weeks of incubation on the vine. Photo by Joe Ogrodnick. 
hybrids were found to be $\mathrm{CR}$ in the berries (Table 2), and none of these pistillateflowered genotypes have $V$. vinifera documented in their pedigree (23).

Ontogenic resistance. On the other hand, of the genotypes classified as OR, the majority (17 of 24) were interspecific hybrids (Table 1). The primary documented source of ontogenic resistance is the European grape (V. vinifera) $(8,11,21)$, which is also thought to be the source of hermaphroditism in grapevine (22). Fifteen of the $17 \mathrm{~V}$. hybrid genotypes classified as OR have hermaphroditic flowers (C. T. Gee and L. Cadle-Davidson, unpublished), suggesting $V$. vinifera as the source of OR in these individuals. Ontogenic resistance requires susceptibility at some point in tissue development, and V. vinifera genotypes in general are excellent donors of powdery mildew susceptibility.

Ontogenic resistance of grape berries was not confined to $V$. vinifera and related genotypes, but was also identified in berries of individual genotypes of native North American grapevines V. labrusca, V. riparia, and $V$. rupestris, suggesting broad conservation of the trait in susceptible individuals of European and some North American species (Table 1). These North American genotypes retained quantitative levels of resistance during their susceptible phase, such that the maximal severity of powdery mildew was lower in the North American OR genotypes than in the $V$. hybrids in the OR group (Table 1). As an exception to this, the highest severity occurred in the persistently susceptible $V$. rupestris ' $\mathrm{R}-65-44$ '.

In the search for genotypes with prolonged susceptibility, we did not expect to identify a phenotype as extreme as that for $V$. rupestris 'R-65-44', which maintains berry susceptibility past veraison on detached berries and much later than any other grapevine tested (Table 1). Further, persistent and heightened susceptibility was unexpected in $V$. rupestris, which is widely characterized as a powdery mildew-resistant Vitis species. Therefore, we checked vine and cluster morphology and confirmed that this genotype had apparently normally developing berries and exhibited other phenotypic traits exemplifying $V$. rupestris, such as red stems and leaf petioles, a bushy habit with shortened internodes, and dioecious flowers (23) (Figs. 4 and 5).

For V. vinifera 'Chardonnay' and V. labruscana 'Concord', ontogenic resistance has been shown to prevent $U$. necator from penetrating beyond the berry cuticle (9). Our results suggest this mechanism is also present in OR individuals in this study. Ontogenically resistant berries significantly inhibited haustorium formation and secondary hyphal growth relative to persistently susceptible V. rupestris 'R-65-44' $(P$ $=0.0005$ ) (Fig. 3). In one genotype, $V$. hybrid 'Red Amber', ontogenic resistance allowed a small proportion of conidia to penetrate, but colony establishment quickly failed. This observation reveals that ontogenic resistance may be expressed at different rates or to different degrees during infection.

Tissue specificity. In this diverse collection, we observed a large disparity in phenotypic classification among sections of the cluster (i.e., rachis, pedicel, berry).
Although 'Concord' was previously shown to develop OR in multiple tissue types but with tissue-specific timing (10), the diverse genotypes in the current study rarely had the same response in all tissues, with only four of 79 genotypes having the same classification on all three tissue types (Tables 1 and 2). In part, this could be explained by the frequent occurrence of susceptibility exhibited in the rachis and pedicel portions

Table 2. Genotypes classified as constitutively resistant

\begin{tabular}{|c|c|c|c|c|c|}
\hline $\mathbf{P I}^{\mathbf{a}}$ & Vitis species $^{\mathbf{b}}$ & Variety $^{c}$ & $\begin{array}{c}\text { Average } \\
\text { severity } \\
(\%)^{d}\end{array}$ & $\begin{array}{c}\text { Rachis } \\
\text { classification }^{\mathrm{e}}\end{array}$ & $\begin{array}{c}\text { Pedicel } \\
\text { classification }^{\mathrm{f}}\end{array}$ \\
\hline 588399 & V. acerfolia & $150-44$ & 0.4 & SU & SU \\
\hline 588324 & V. acerifolia & Unknown & 0.0 & SU & $\mathrm{SU}$ \\
\hline 588325 & V. acerifolia & Unknown & 0.0 & $\mathrm{CR}$ & NS \\
\hline 588218 & $V$. cinerea & B 47 & 1.3 & SU & NS \\
\hline 588220 & $V$. cinerea & B 55 & 1.2 & $\mathrm{SU}$ & $\mathrm{SU}$ \\
\hline 588222 & $V$. cinerea & C-66-7 & 0.0 & SU & NS \\
\hline 483176 & V. hybrid & Tom's Favorite & 0.4 & SU & OR \\
\hline 588563 & V. hybrid & Minn 78 & 0.0 & $\mathrm{CR}$ & OR \\
\hline 588572 & V. hybrid & R $67-76$ & 0.0 & SU & SU \\
\hline 588573 & V. hybrid & D-1-30 & 0.3 & SU & SU \\
\hline 483145 & V. labrusca & Rem 26-75 & 0.0 & NS & NS \\
\hline 483148 & V. labrusca & Rem 46-75 & 0.6 & $\mathrm{CR}$ & NS \\
\hline 483150 & V. labrusca & Rem NE 8 & 0.4 & NS & NS \\
\hline 483152 & V. labrusca & Rem NE 11 & 0.0 & $\mathrm{CR}$ & NS \\
\hline 483155 & V. labrusca & Rem NE 15 & 0.0 & $\mathrm{CR}$ & OR \\
\hline 483158 & V. labrusca & Rem NE 23 & 0.0 & $\mathrm{CR}$ & $\mathrm{CR}$ \\
\hline 483160 & V. labrusca & Rem NE 25 & 1.0 & CR & OR \\
\hline 255189 & V. riparia & Urbana 1 & 0.0 & OR & OR \\
\hline 483165 & V. riparia & Rem 55-75 & 0.0 & $\mathrm{CR}$ & NS \\
\hline 483170 & V. riparia & Rem 73-76 & 0.0 & SU & $\mathrm{SU}$ \\
\hline 483171 & V. riparia & Rem 77-76 & 0.3 & NS & NS \\
\hline 483172 & V. riparia & Rem 81-76 & 0.0 & NS & SU \\
\hline 483173 & V. riparia & Rem 82-76 & 0.3 & SU & NS \\
\hline 483174 & V. riparia & Rem 83-76 & 0.3 & SU & SU \\
\hline 483175 & V. riparia & Rem 85-76 & 0.7 & $\mathrm{CR}$ & NS \\
\hline 588258 & V. riparia & 14 & 0.4 & SU & SU \\
\hline 588259 & V. riparia & 37 & 0.0 & SU & $\mathrm{SU}$ \\
\hline 588260 & V. riparia & 64 & 0.0 & SU & $\mathrm{SU}$ \\
\hline 588261 & V. riparia & 74 & 0.0 & $\mathrm{SU}$ & $\mathrm{SU}$ \\
\hline 588262 & V. riparia & 89 & 0.0 & OR & $\mathrm{SU}$ \\
\hline 588269 & V. riparia & $62-8-160$ & 0.0 & NS & $\mathrm{CR}$ \\
\hline 588270 & V. riparia & $62-9-44$ & 0.0 & NS & NS \\
\hline 588274 & V. riparia & $62-11-42$ & 1.3 & NS & NS \\
\hline 588276 & V. riparia & $62-8-138$ & 0.0 & NS & NS \\
\hline 588304 & V. riparia & Unknown & 0.0 & SU & NS \\
\hline 588347 & V. riparia & B 50 & 0.0 & $\mathrm{CR}$ & OR \\
\hline 588353 & V. riparia & RA-66-7 & 0.1 & NS & NS \\
\hline 588400 & V. riparia & Unknown & 0.0 & CR & $\mathrm{CR}$ \\
\hline 588406 & V. riparia & Meissner 13 & 0.4 & NS & SU \\
\hline 588435 & V. riparia & $2 \mathrm{~F}$ & 0.0 & NS & OR \\
\hline 588437 & V. riparia & $1 \mathrm{~F}$ & 0.0 & OR & SU \\
\hline 588438 & V. riparia & Unknown & 0.2 & NS & NS \\
\hline 588455 & V. riparia & Unknown & 0.0 & SU & NS \\
\hline 588456 & V. riparia & Unknown & 1.2 & SU & SU \\
\hline 588483 & V. riparia & Rem NE 21 & 0.1 & $\mathrm{CR}$ & OR \\
\hline 588565 & V. riparia & Grem & 0.0 & NS & SU \\
\hline 588568 & V. riparia & Crosby rootstock & 0.0 & SU & $\mathrm{SU}$ \\
\hline 588392 & $V . \times$ andersonii & Unknown & 0.0 & SU & SU \\
\hline 588391 & V. $\times$ champinii & Unknown & 0.6 & OR & OR \\
\hline 588257 & $V . \times$ novae-angliae & Unknown & 0.0 & CR & CR \\
\hline
\end{tabular}

${ }^{\text {a }} \mathrm{PI}=$ plant introduction number, a unique identifier for each genotype in the GRIN database, where PI is linked with additional information related to that genotype: http://www.ars-grin.gov/npgs/ index.html (23).

${ }^{\mathrm{b}}$ Species listed for each genotype, taken from the GRIN database. Vitis interspecific hybrids are listed as V. hybrid.

${ }^{c}$ Variety listed for each genotype, taken from the GRIN database. Genotypes with no variety recorded listed as unknown.

${ }^{\mathrm{d}}$ Average disease severity of all clusters, averaged among all years.

${ }^{\mathrm{e}}$ Classification of the rachis using the same criteria developed for berry data.

${ }^{\mathrm{f}}$ Classification of the pedicel using the same criteria developed for berry data. 

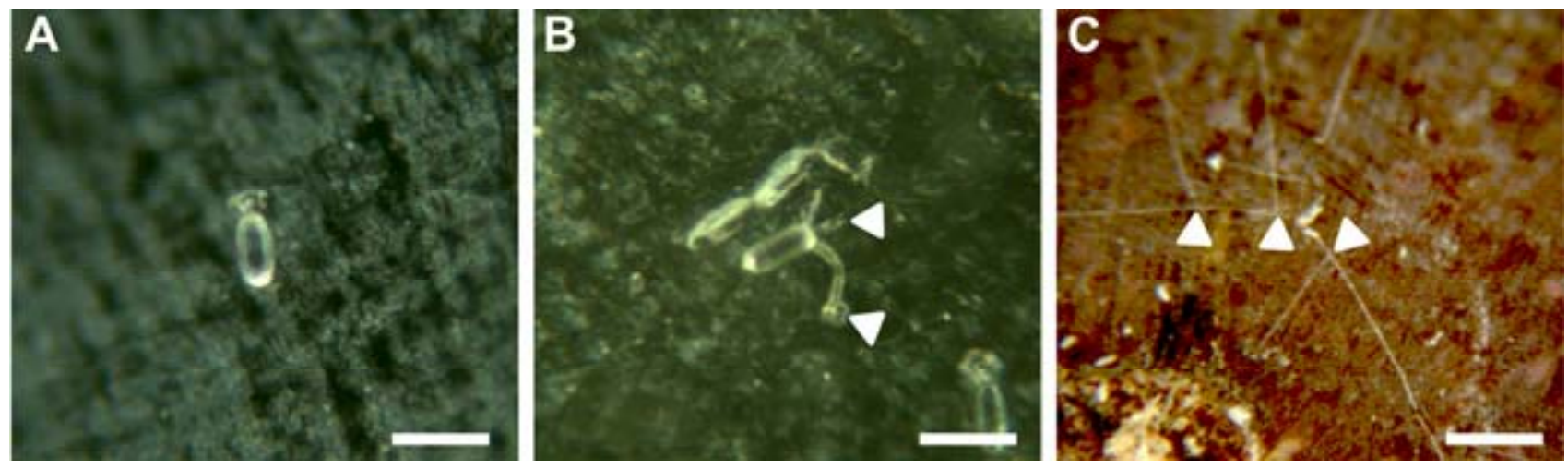

Fig. 3. Epi-illuminescence micrographs showing the three categories of germinated conidia used to classify pathogen growth on detached berries. Individual germinated conidia were classified as developing as follows: A, a germinated conidium with a primary appressorium but no further growth; $\mathbf{B}$, a germinated conidium with a primary appressorium and secondary hyphae (arrows); and $\mathbf{C}$, a germinated conidium showing extensive and branching secondary hyphae (arrows). Note the berry pigmentation in $\mathbf{C}$ reflecting the postveraison status of this persistently susceptible, red-berried genotype, Vitis rupestris 'R-65-44' (PI: 588224). Scale bars represent $50 \mu \mathrm{m}$ in panels $\mathbf{A}$ and $\mathbf{B}$, and $100 \mu \mathrm{m}$ in panel $\mathbf{C}$.

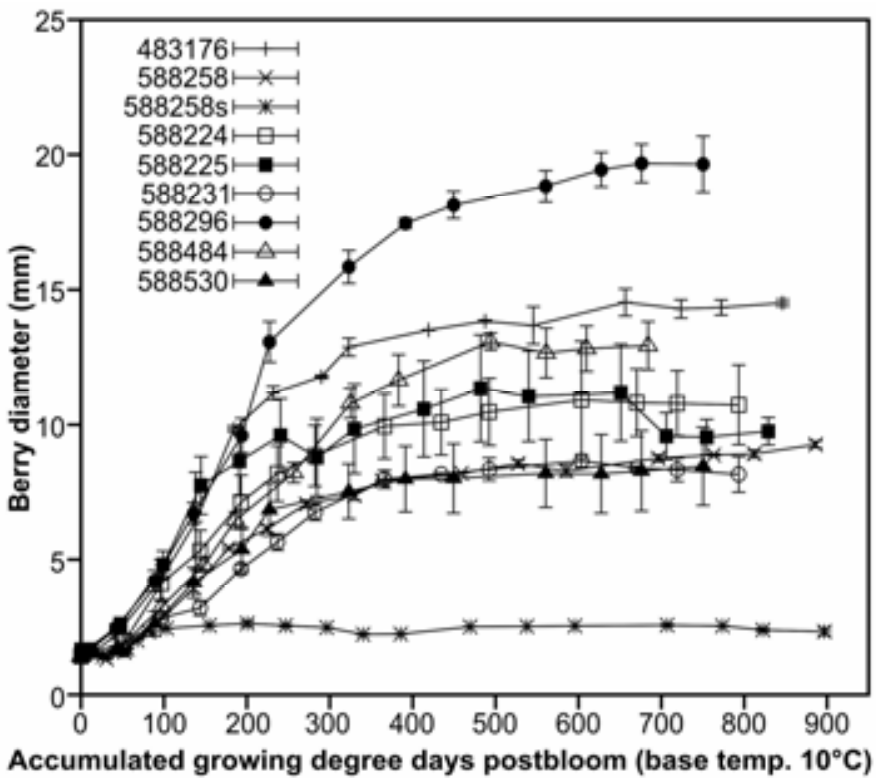

Fig. 4. Berry size development of persistently susceptible Vitis rupestris 'R-65-44' (PI: 588224) is similar to ontogenically resistant and constitutively resistant genotypes. Berry diameter was measured every 4 days from the same 20 berries on one cluster on each adjacent replicate vine, and the largest two berries from each measurement were averaged to eliminate the influence of nondeveloping (shot) berries on means. Data were collected for the genotypes: V. hybrid 'Tom's Favorite' (PI: 483176); V. riparia '14' (PI: 588258); V. rupestris 'R-65-44' (PI: 588224); V. rupestris 'R-65-47' (PI: 588225); V. rupestris 'Alphonse de Serres' (PI: 588231); V. hybrid 'Red Amber' (PI: 588296); V. hybrid 'NY 65.591.1' (PI: 588484); and V. hybrid 'NY 65.556.5' (PI: 588530). One replicate of V. riparia '14' $(588258 \mathrm{~s})$ consisted entirely of shot berries. Error bars represent plus or minus one standard deviation.

of clusters in this collection. While only one genotype had persistently susceptible fruit, 50 genotypes had persistently susceptible rachises and/or pedicels. This finding opens new avenues of research into the mechanism of ontogenic resistance. Having genotypes that express susceptibility asynchronously among the various tissue types of the cluster could allow for reduction of environmental effects, compared to studying clusters from different vines or even from the same vine. It should be noted, however, that our method for describing the resistance phenotypes of berries was not as successful in categorizing the rachis and pedicel phenotypes. While the berries of only four genotypes were classified NS, 21 and 18 genotypes were NS for the pedicel and rachis, respectively. One aspect that caused several genotypes to have NS pedicel and rachis phenotypes was an apparent gain of susceptibility (data not shown).

Shot berries. Many genotypes in this study exhibited high proportions of undeveloped berries (i.e., shot berries) that arose from failed fertilization events, were stunted in growth and development, and typically remained small and green all season (5). These berries remained susceptible throughout the growing season, and surprisingly, shot berries on many CR genotypes remained fully susceptible regardless of the inoculation time. Addition- ally, even during the earliest stages of berry development (0-6 DPB) on CR genotypes, there were differences between shot berries and normally developing berries that allowed infection and colonization of unfertilized flowers. Thus, aspects of fertilization or seed development may be somehow linked to resistance, and this may provide an additional avenue by which the genetic basis of ontogenic resistance could be investigated. Due to shot berries having susceptibility unrepresentative of normally developing berries, we did not include data from shot berries in our analyses. A potential benefit of selecting against shot berry production in breeding programs might be to enhance the impact of ontogenic resistance by eliminating such persistent inoculum sources.

This project disclosed a substantial amount of temporal and tissue-specific variation in susceptibility to powdery mildew. For investigating the basis of ontogenic resistance, some of this variation could prove useful. By identifying genotypes that are either OR (including several that appear to be temporally distinct) or SU, the basis of ontogenic resistance could be uncoupled from other aspects of berry development occurring synchronously. Further, the discovery of a persistently susceptible genotype will allow for genetic studies to be carried out investigating the inheritance of ontogenic resistance.

\section{ACKNOWLEDGMENTS}

We thank Jim Booth and the Cornell University Department of Biological Statistics and Computational Biology for significant help with the statistical analysis. Michael Shields is graciously thanked for authoring the software used in the vineyard, and for consulting on all datahandling issues encountered in this project. Nancy Consolie, Jason Coburn, Jeff Quinto, Cally Geartz, Claire Healy, Peter Cousins, Susan Switras-Meyer, Carl Meyer, Kristen Hutchinson, Sara Dean, Grace Lynch, Laura Wakefield, Rachel Thomas, and the ARS-PGRU staff are appreciatively acknowledged for technical support with the vineyard aspects of this study. This research 


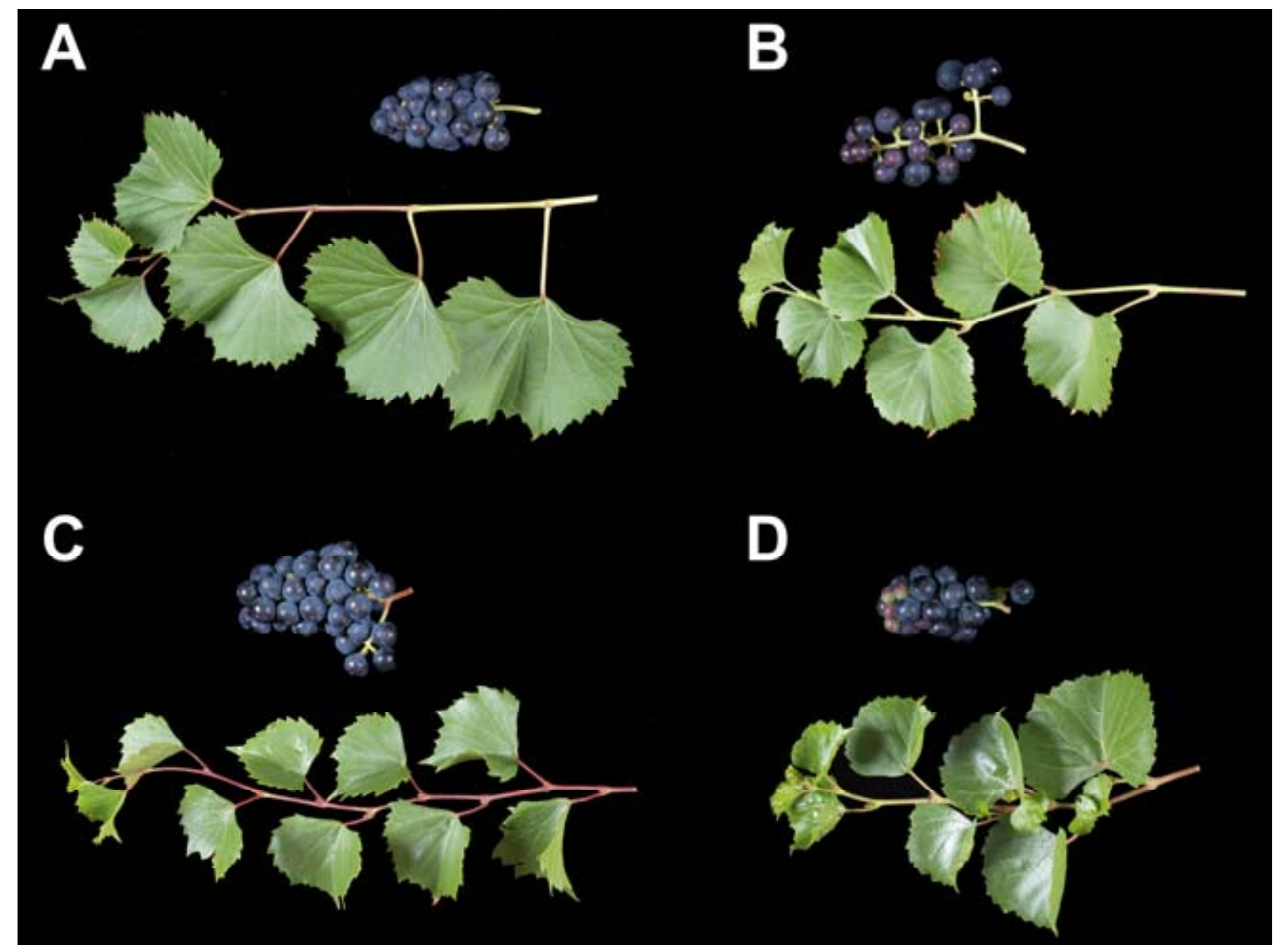

Fig. 5. Clusters and shoots from the four genotypes of Vitis rupestris included in this study. The single persistently susceptible (SU) genotype, A, V. rupestris 'R-65-44' (PI: 588224), undergoes normal development and is representative of the species V. rupestris. The other genotypes presented for comparison are B, V. rupestris 'R-65-47' (PI: 588225); C, V. rupestris 'Alphonse de Serres' (PI: 588231); and D, V. rupestris 'RU-66-2' (PI: 588401). Photos by Joe Ogrodnick.

was supported by USDA-ARS CRIS Project 1910-21220-002-00D at the Grape Genetics Research Unit and by a scholarship to C.T.G. from the American Society for Enology and Viticulture, Eastern Section.

\section{LITERATURE CITED}

1. Bailey, L. H. 1934. The species of grapes peculiar to North America. Gentes Herbarum 3:151-244

2. Basson, S., Dewaele, D., and Meyer, A. J. 1992. Effect of host plant-age on population development and pathogenicity of Ditylenchus destructor on peanut. J. Nematol. 24:310-314.

3. Chantret, N., Mingeot, D., Sourdille, P., Bernard, M., Jacquemin, J. M., and Doussinault, G. 2001. A major QTL for powdery mildew resistance is stable over time and at two development stages in winter wheat. Theor. Appl. Genet. 103:962-971.

4. Develey-Rivière, M.-P., and Galiana, E. 2007. Resistance to pathogens and host developmental stage: A multifaceted relationship within the plant kingdom. New Phytol. 175:405-416.

5. Ebadi, A., Sedgley, M., May, P., and Coombe, B. G. 1996. Seed development and abortion in Vitis vinifera L., cv. Chardonnay. Int. J. Plant Sci. 157:703-712.

6. Farinho, M., Coelho, P., Carlier, J., Svetleva, D., Monteiro, A., and Leitao, J. 2004. Mapping of a locus for adult plant resistance to downy mildew in broccoli (Brassica oleracea convar. Italica). Theor. Appl. Genet. 109:1392-1398.

7. Ficke, A., Gadoury, D. M., Godfrey, D., and Dry, I. B. 2004. Host barriers and responses to Uncinula necator in developing grape berries.
Phytopathology 94:438-445.

8. Ficke, A., Gadoury, D. M., and Seem, R. C. 2002. Ontogenic resistance and plant disease management: A case study of grape powdery mildew. Phytopathology 92:671-675.

9. Ficke, A., Gadoury, D. M., Seem, R. C., and Dry, I. B. 2003. Effects of ontogenic resistance upon establishment and growth of Uncinula necator on grape berries. Phytopathology 93:556-563.

10. Gadoury, D. M., Seem, R. C., Ficke, A., and Wilcox, W. F. 2001. The epidemiology of powdery mildew on concord grapes. Phytopathology 91:948-955.

11. Gadoury, D. M., Seem, R. C., Ficke, A., and Wilcox, W. F. 2003. Ontogenic resistance to powdery mildew in grape berries. Phytopathology 93:547-555.

12. Goggin, F. L., Shah, G., Williamson, V. M., and Ullman, D. E. 2004. Developmental regulation of Mi-mediated aphid resistance is independent of Mi-1.2 transcript levels. Mol. PlantMicrobe Interact. 17:532-536.

13. Hoffman, L. E., Wilcox, W. F., Gadoury, D. M., and Seem, R. C. 2002. Influence of grape berry age on susceptibility to Guignardia bidwelli and its incubation period length. Phytopathology 92:1068-1076.

14. Kennelly, M. M., Gadoury, D. M., Wilcox, W. F., Magarey, P. A., and Seem, R. C. 2005. Seasonal development of ontogenic resistance to downy mildew in grape berries and rachises. Phytopathology 95:1445-1452.

15. Kus, J. V., Zaton, K., Sarkar, R., and Cameron, R. K. 2002. Age-related resistance in Arabidopsis is a developmentally regulated defense response to Pseudomonas syringae. Plant Cell 14:479-490.

16. Panter, S. N., and Jones, D. A. 2002. Agerelated resistance to plant pathogens. Adv. Bot. Res. 38:251-280.

17. Pearson, R. C., and Gadoury, D. M., eds. 1992. Powdery Mildews of Grape. Plant Diseases of International Importance. Vol. 3. J. Kumar et al., eds. Prentice Hall, New Jersey. pp. 129146.

18. Populer, C. 1978. Changes in host susceptibility with time. Plant Disease: An advanced treatise. Vol. 2. J. G. Horsfall and E. B. Cowling, eds. Academic Press, New York. pp. 239-260.

19. Rausher, M. D. 2001. Co-evolution and plant resistance to natural enemies. Nature 411:857864.

20. Roy, R. R., and Ramming, D. W. 1990. Varietal resistance of grape to the powdery mildew fungus, Uncinula necator. Fruit Varieties J. 44:149-155

21. Stark-Urnau, M., and Kast, W. K. 1999. Development of ontogenic resistance to powdery mildew in fruit of differentially susceptible grapevines (cvs. Trollinger and Lemberger). Mitteilungen Klosterneuburg 49:186189.

22. This, P., Lacombe, T., and Thomas, M. R 2006. Historical origins and genetic diversity of wine grapes. Trends Genet. 22:511-519.

23. U.S. Dep. Agric.-Agric. Res. Serv., National Genetic Resources Program. Germplasm Resources Information Network - (GRIN). National Germplasm Resources Laboratory, Beltsville, MD. Online database. http://www. ars-grin.gov/npgs/index.html. 